\title{
Grau de Monopólio e Testes de Granger-Causalidade entre Custos e Preços na Indústria Brasileira*
}

\author{
Luiz Dias Bahia**
}

Sumário: 1. Introdução; 2. Formação de preços em Kalecki; 3. Testes de causalidade; 4. Conclusão.

Palavras-chave: grau de monopólio; testes de causalidade de Granger; barganha intersetorial.

Códigos JEL: D4; L1.

$\mathrm{O}$ artigo busca analisar o papel das relações intersetoriais entre fornecedores e compradores de insumos em condições de oligopólio bilateral, por meio da abordagem kaleckiana de grau de monopólio. Conclui-se que a barganha intersetorial pode alterar o grau de monopólio dos setores envolvidos e, conseqüentemente, de toda economia. A seguir desenvolve-se testes de causalidade de Granger entre preços de insumos e preços do produto final para dez gêneros da indústria de transformação. A conclusão principal é que, na barganha intersetorial entre fornecedores e compradores oligopolistas de insumos, geralmente cabe aos compradores a maior capacidade de influenciar os preços.

This paper analyses the role of relationship among suppliers and buyers of inputs in condition of bilateral oligopoly, using the kaleckian concept of monopoly degree. It finds that the tradeoff among sectors alters the degree of monopoly of the sectors, and consequently of the economy as a whole. Then, Granger's causality tests are done among input prices and final product prices for 10 sectors of the manufacturing industry. The main cvonclusion is that the buyers have more ability to influence the prices than the suppliers.

\section{Introdução}

Dentre as barganhas que ocorrem entre fornecedores e clientes numa economia, a do oligopólio bilateral é a mais complexa. Desde a abordagem de Galbraith (1954) até Azzam (1996), o problema vem sendo abordado, mas permanece ainda

\footnotetext{
*Artigo recebido em mar. 2001 e aprovado em mai. 2003. O autor agradece as sugestões de Afonso Henriques Borges Ferreira, Marco Flávio Resende, Thiago Pereira, Luciana Santos e dois pareceristas anônimos, isentando-os dos erros remanescentes.

${ }^{* *}$ DISET/IPEA.
} 
em aberto. O objetivo deste artigo é abordar o problema, do ponto de vista teórico e empírico, partindo de um marco teórico kaleckiano.

O artigo está organizado de forma simples. Na próxima parte é feita a abordagem teórica. Na seguinte, a empírica. E na última, apresentamos as conclusões.

\section{Formação de Preços em Kalecki}

\subsection{A hipótese de custos constantes}

A hipótese de que os produtos industriais estão sujeiros a custos médio e marginais constantes, que Kalecki adota, vem de Sraffa $(1988)^{1}$ e foi confirmada por estudos empíricos. ${ }^{2}$

Mesmo levando-se em consideração tais estudos, eles implicam que nas relações intersetoriais da indústria, haja apenas um mero repasse de custos. Essa parece ser a posição de Kalecki (1983b), quando afirma que "dado um grau de monopólio, os preços dos produtos acabados são funções lineares homogêneas dos preços das matérias-primas, de um lado, e, de outro, dos custos de mão-de-obra em todas as etapas de produção".

Como as economias capitalistas com razoável desenvolvimento apresentam significativos graus de concentração na indústria, ${ }^{3}$, seu mercado de fatores de produção deve se constituir de oligopólios bilaterais. Nesse caso, não há curvas de oferta e demanda de fatores definidas, e o preço dos fatores de produção se transforma no resultado de uma barganha sem contornos definidos (Bain, 1952). Esse problema deixaria de existir, caso o comprador enfrentasse uma curva de oferta do fornecedor perfeitamente elástica, como mostra Bain (1952). Isso justificaria a posição de Kalecki, já que ele supõe serem os preços industriais constantes até o nível de plena utilização. Mas para as relações intersetoriais não desempenharem nenhum papel na formação de preços ao longo da cadeia produtiva, dado o grau de monopólio, temos que supor custos diretos constantes; e para considerar custos diretos constantes, temos de supor que as relações intersetoriais não têm papel na

\footnotetext{
${ }^{1}$ Esse trabalho está relacionado nas referências bibliográficas em sua tradução brasileira de 1988.

${ }^{2}$ Ver o desenvolvimento de funções de produção de engenharia, como em Chenery (1949), que levam a isoquantas descontínuas e, portanto, a custos médios e marginais constantes no intervalo efetivamente operacional da planta instalada.

${ }^{3}$ Ver por exemplo Liebeskind et alii (1996) que calcula, para a indústria dos EUA em 1989 um C4 médio de 48,37\% e um H-H médio de 0,1146 (pode-se esperar haver um grau de concentração até maior nas indústrias mais significativas e com grau maior de maturidade porque, como observam os autores, cada indústria tem o mesmo peso no cálculo dos valores apresentados).
} 
formação de preço, dado o grau de monopólio.

Para evitar uma tautologia, temos de esperar que o grau de monopólio exerça aí papel relevante. O que nos leva a examinar o conceito de grau de monopólio em Kalecki.

\subsection{A hipótese original de Lerner}

O conceito de grau de monopólio original, em que Kalecki se baseou nas suas primeiras formulações, foi proposto por Lerner (1934). A referência teórica desse último autor é a economia do bem-estar de Pareto. Nela, ele considera que o mal do monopólio está apenas em restringir a liberdade do consumidor. Lerner descarta a análise marshalliana do excedente consumidor devido à impossibilidade de agregação de um conjunto de mercadorias. (Mais recentemente, Willig (1976b,a) supera essa dificuldade, através de uma função indireta de utilidade para bens múltiplos).

A medida de grau de monopólio de Lerner, do ponto de vista do consumidor, parte do fato de que, em condições normais, o deslocamento na margem da curva de bem-estar da comunidade seria proporcional ao preço e, na curva de transformação, proporcional ao custo marginal. Logo, a medida do grau de monopólio seria a divergência entre o preço e o custo marginal.

Do ponto de vista da firma, Lerner considera no monopólio uma curva de custo médio horizontal. Assim, a taxa entre o retorno do monopólio e sua receita total coincidiria com a taxa entre a divergência do preço para o custo marginal $([P-C] / P)$, o que é a medida do grau de monopólio.

Duas questões formuladas por Lerner são deixadas como herança (e problemas) para Kalecki. Primeiro, o conceito de indústria como uma reunião de firmas produzindo seu produto específico (já que se considera mercadorias iguais aquelas substituíveis na margem uma pela outra) é em grande medida 'ad hoc'. Segundo, pelos motivos já expostos pode-se deduzir que o monopolista estaria enfrentando uma curva de fatores de produção infinitamente elástica, logo pode-se simplesmente agregar todas as firmas ao longo da cadeia produtiva, sem considerar o papel das relações intersetoriais.

\subsection{As primeiras formulações de Kalecki}

As primeiras formulações kaleckianas do grau de monopólio, apesar de usarem o conceito de Lerner, buscam delimitar a manipulação de preços devido a fatores institucionais e nãopor se romper com a liberdade de escolha no mercado de Lerner. 
A construção de Kalecki parte de uma firma representativa, com um dado equipamento de capital, que produz, em um dado momento, uma quantidade $x \mathrm{e}$ o vende a um preço $p$. O grau de monopólio $\mu$ seria, assim, a razão entre o produto de todas as firmas, líquido dos custos marginais de curto prazo (depreciação, ordenados, salários e matérias-primas), e o produto bruto (somatório, para todas as firmas, de $x$ e $p$.

A conclusão de Kalecki é que a proporção de rendimento capitalista e 'overheads' para o produto bruto da economia, ou seja, dada distribuição de renda, é uma expressão bastante aproximada do grau de monopólio médio da economia.

Três problemas surgem dessas formulações. Primeiro, Kalecki não considera a integração vertical dos setores. Segundo, o grau de monopólio pode se alterar segundo a variação de produção entre os setores, o que torna sua influência sobre a distribuição de renda carente de transitividade. Finalmente, persistem os problemas apontados em Lerner: a ausência de um conceito acabado de indústria, junto às dificuldades de agregação e de se abranger relações intersetoriais.

\subsection{As formulações mais definitivas de Kalecki}

Num conjunto de trabalhos de fins da década de 30 e início da de 40, onde Kalecki conjuga o uso de instrumental ortodoxo com a curva de demanda quebrada de Hall e Hitch (1988), ${ }^{4}$ também devida a Sweezy (1939), ocorre uma novidade relevante: a preocupação inédita com a interdependência das firmas sob oligopólio, através da definição da imperfeição do mercado como proporcional à taxa entre o preço médio da indústria e o da firma sob análise.

Em Kalecki (1943), ocorre outro avanço na interdependência entre firmas da indústria: se os custos de uma firma aumentarem isoladamente, espera-se que seus preços variem menos em relação a uma dada variação de custos do que se os custos de seus concorrentes tiverem aumentado igualmente. O processo de agregação, contudo, é semelhante aos anteriores, ou seja, uma média ponderada pelo produto de cada firma.

Na Teoria da Dinâmica Econômica (TDE), Kalecki se afasta definitivamente da ortodoxia de Lerner e passa a considerar que na fixação de preço pela firma leva-se em consideração seus custos diretos médios (não mais custos marginais) e os preços de outras firmas que produzem produtos similares. Kalecki (1983a) volta ao problema da formação de preços, mas, como mostra Kriesler (1987), essa nova forma pode se considerada como uma variante da feita na TDE.

\footnotetext{
${ }^{4}$ Este artigo está citado na bibliografia em sua tradução de 1988.
} 
Persistem, entretanto, dois problemas: o conceito de indústria e as relações intersetoriais entre firmas. Quanto ao primeiro, Kriesler (1987) enfatiza que na agregação do preço médio pode estar ocorrendo um viés, pois o produto não é independente do preço. Quanto ao segundo, Kalecki, ao enumerar as principais influências sobre o grau de monopólio, não enfatiza as relações intersetoriais da indústria.

Esse último ponto é particularmente relevante. Como enfatiza Bain (1952), essas relações são resultado de uma barganha entre oligopólios, onde "não há uma real curva de demanda nem uma real curva de oferta", caindo a determinação de preço em um processo de barganha que pode variar dentro de "largos limites". O resultado, segundo Bain, é um quadro de incerteza quanto à formação de preços e a distribuição de renda. Ou seja, temos aqui mais um determinante, não reconhecido por Kalecki, que pode influenciar o grau de monopólio de toda indústria ou economia.

\subsection{A influência das relações intersetoriais no grau de monopólio}

O objetivo desta seção é reunir o que foi abordado nas seções anteriores para mostrar, em nível formal, que as relações intersetoriais na indústria podem alterar o grau de monopólio, como abordado por Kalecki.

Kalecki inicia sua abordagem denominando o total de salários de $W$; o total de custos de matérias-primas de $M$; e a razão entre o total de rendimentos e o total de custos diretos de $k$. Assim, teríamos:

$$
\text { custos indiretos }+ \text { lucros }=(k-1)(W+M)
$$

Enfatiza-se que $k$ é função do grau de monopólio. A partir dessa expressão, o autor chega a sua conhecida formulação para a participação dos salários no valor agregado:

$$
w=\frac{1}{1+(k-1)(j+1)}
$$

em que $j$ é a razão entre os custos das matérias-primas e da mão-de-obra.

Conclui-se, então, que a parcela relativa de salários no valor agregado é determinada pelo grau de monopólio $(k)$ e pela razão entre custos de matéria-primas e os custos de mão-de-obra $(j)$. Mais à frente, levando em consideração a crítica de que sua agregação do grau de monopólio também depende da composição industrial, o autor considera esse último fator como outro determinante da distribuição de renda calculada na equação anterior. 
Seguindo Sawyer (1985), tentaremos derivar uma expressão análoga à anterior, considerando uma economia na qual há apenas dois setores industriais. O setor A compra matéria-prima, e contrata mão-de-obra e vende todo seu produto como insumo para o setor B, que compra esse insumo e contrata mão-de-obra, vendendo seu produto para o mercado. ${ }^{5}$ Assim, teríamos:

$$
\begin{gathered}
S_{a}=\left(k_{a}-1\right)\left(W_{a}+M_{a}\right) \\
S_{b}=\left(k_{b}-1\right)\left(W_{b}+R_{a}\right) \\
R_{a}=k_{a}\left(W_{a}+M_{a}\right) \\
W_{i}=t_{i} W \\
M_{a}=j W_{a}
\end{gathered}
$$

em que:

$S$ são lucros e ordenados dos setores A e B;

$k$ são os graus de monopólio dos setores A e B;

$W$ são o total de salários dos setores A e B;

$M_{a}$ é o total de matérias-primas usadas por A;

$R_{a}$ é o produto total do setor $\mathrm{A}$;

$t$ é a parcela do salário de toda economia no setor $i$; e $j$ é a proporção do valor da matéria-prima em termos de salários pagos no setor A.

Podemos fazer:

$$
\begin{aligned}
& S=S_{a}+S_{b} \\
& w=\frac{W}{W+S}
\end{aligned}
$$

\footnotetext{
${ }^{5}$ Cabe esclarecer dois pontos. Primeiro, a consideração de um setor produtor de matériaprima busca reproduzir o papel dado por Kalecki ao preço desses produtos frente ao dos salários dos trabalhadores para a determinação da distribuição de renda. Segundo, a consideração de apenas um elo intersetorial não altera a generalidade da barganha proposta, pois a inclusão de mais setores apenas tornaria mais complexo a determinação do resultado final das barganhas, pois essas seriam interdependentes. Além disso, a consideração de casos reais seria proibitiva para efeitos de exposição (ver a extrema complexidade de relações intersetoriais de complexos industriais em Haguenauer et alii (1984).
} 
em que $S$ é o total de lucros mais ordenados e $w$ é a parcela dos salários no valor agregado.

Substituindo as relações anteriores, temos:

$$
w=\frac{1}{1+\left(k_{b}-1\right) t_{b}+t_{a}(1+j)\left(k_{a} k_{b}-1\right)}
$$

Notamos que, na equação (1), a participação dos salários no valor agregado depende, como estipulado por Kalecki, do grau de monopólio, do valor dos salários em termos do valor das matérias-primas empregadas e da composição industrial.

Suponhamos que o setor A, ao vender seu produto a B, entre em uma barganha para definir seu preço. Consideremos que o resultado possa ser expresso em uma redução do grau de monopólio de $A\left(k_{a}-e\right)$, e que o grau de monopólio de $\mathrm{B}$ aumente o mesmo em termos absolutos $\left(k_{b}+e\right)$. Fazendo essa modificação na equação (1), teremos:

$$
w=\frac{1}{\left[1+\left(\left(k_{b}-1\right) t_{b}+t_{a}(j+1)\left(k_{a} k_{b}-1\right)\right)\right]+e\left[t_{b}+t_{a}(j+1)\left(k_{a}-k_{b}-e\right)\right]}
$$

Notamos que a distribuição de renda foi alterada: no denominador da equação (2), o segundo termo entre colchetes não existia na equação (1). A única alteração feita foi nos graus de monopólio de cada setor. Logo, a causa da mudança na distribuição foi a mudança no grau de monopólio de toda a economia. Cowling (1978) mostra como o poder dos gerentes, numa economia gerencial, pode afetar a distribuição de valor agregado entre os proprietários do capital e a gerência. Sua derivação do grau de monopólio é semelhante a Kalecki (1938). Contudo, esse último autor considera a distribuição de renda entre salários e lucros, incluindo nos lucros os salários dos gerentes. Logo, esse poder dos gerentes não altera a distribuição funcional de renda como exposta nessa seção.

Deve-se salientar que esse resultado pressupõe que os níveis de utilização de capacidade sejam mantidos antes e depois da mudança na barganha intersetorial. Além disso, é necessário que não se tenha atingido o nível de plena utilização de capacidade.

O sentido de termos deduzido a equação (2) não foi o de inferir o impacto de relações intersetoriais na economia. Primeiro, porque é essa uma economia simplificada em excesso. Segundo, porque o resultado pode ser um ou outro, uma vez definidos os parâmetros. Nosso objetivo é apenas mostrar, de forma simplificada, 
que o grau de monopólio, como teorizado por Kalecki, pode ser alterado se supusermos que os preços dos insumos são objeto de uma barganha, cujo resultado, como afirma Bain (1952), pode variar bastante. ${ }^{6}$

A razão intuitiva que explica tal alteração pode ser dividida em duas. Primeiro, quando o grau de monopólio das firmas se altera, como elas produzem distintos valores agregados, altera-se também o grau de monopólio de toda a economia. ${ }^{7}$ Em segundo lugar, quando consideramos um encadeamento de setores, notamos que o grau de monopólio nestes reunido é uma função não linear de seus respectivos graus de monopólio.

Enfatizamos, mais uma vez, que nosso objetivo não é teorizar sobre a distribuição de renda em Kalecki, mas apenas utilizá-la como instrumento para demonstrar que as relações intersetoriais na indústria podem mudar seu grau de monopólio. Uma abordagem específica da distribuição de renda exigiria a consideração de outros aspectos, como o setor serviços, sindicatos de trabalhadores, etc.

Estamos em condições, portanto, de responder à questão feita na seção 2.1. De fato, quando Kalecki afirma que, dado o grau de monopólio, o preço final de um encadeamento entre setores é função homogênea linear dos preços das matériasprimas de um lado e, de outro, dos custos de mão-de-obra em todas as etapas de produção, ele parece estar correto. O que mostramos aqui é que a barganha intersetorial pelos preços dos insumos pode alterar o grau de monopólio dos setores e, conseqüentemente, de toda a economia. Ou seja, as relações intersetoriais podem mudar o grau de monopólio e, assim, o nível em que os preços dos produtos acabados são função homogênea linear dos preços das matérias-primas e dos custos da mão-de-obra.

\footnotetext{
${ }^{6} \mathrm{O}$ resultado obtido não é, entretanto, uma extensão teórica do obtido em Sawyer (1985). Apesar de se ter usado variáveis como definidas por esse último autor, seu objetivo teórico é apenas o de confirmar a afirmativa de Kalecki de que a distribuição de renda depende da composição setorial do produto. Nosso objetivo é diverso. Buscamos mostrar que, considerada a barganha intersetorial de insumos, o grau de monopólio de toda indústria ou de toda economia pode variar, mesmo que o grau de monopólio, em termos consolidados, de todos os setores, não tenha sido alterado (no exemplo acima, a soma dos graus de monopólio dos setores A e B continuou a mesma, apesar do grau de monopólio total ter se alterado).

${ }^{7} \mathrm{~A}$ barganha intersetorial não altera os salários em valor absoluto mas, ao alterar o valor absoluto dos lucros, altera seu valor relativo ao lucro total, que é o que a distribuição entre salários e lucros tenta captar; o valor total de lucros se altera porque, como cada setor é responsável por uma parcela distinta da composição de produção setorial, a alteração do grau de monopólio de cada um altera o valor total dos lucros.
} 


\section{Testes de Causalidade}

Procurando testar empiricamente a existência de uma barganha no mercado de fatores entre fornecedores e compradores, construímos duas séries de preço: ${ }^{8}$ uma para o produto final e outra para os cinco principais fornecedores de cada gênero selecionado. A idéia foi fazer testes de causalidade de Granger entre preços de insumos e preços finais para cada gênero selecionado. O período cobriu janeiro de 1978 a dezembro de 1998.

\subsection{A transição do modelo teórico para o empírico}

O modelo de formação de preço intersetorial da seção 2.5 poderia ser resumido nas seguintes equações:

$$
\begin{gathered}
p_{t}^{c}=\left(1+m_{t}^{c}\right)\left(c_{t}^{c}+s_{t}^{c}\right) \\
p_{t}^{f}=\left(1+m_{t}^{f}\right)\left(c_{t}^{f}+s_{t}^{f}\right) \\
c_{t}^{c}=p_{t}^{f}
\end{gathered}
$$

onde:

$p=$ preço da cada setor, identificado como cliente (letra c) ou fornecedor (letra f) no instante $t$;

$m=$ mark-up, com as mesmas indicações de $p$;

$c=$ custos diretos de insumos, com as mesmas indicações de $p$;

$s=$ salários diretos, com as mesmas indicações de $p$.

Consideramos a hipótese mais realista de que essa relação intersetorial ocorra num oligopólio bilateral. Entretanto, como afirma Bain (1952), nesse caso não há nem uma verdadeira demanda de mercado nem uma curva de oferta de mercado verdadeira, concluindo que clientes e fornecedores determinarão preço e produto por barganha, e as chamadas forças de mercado impessoais estão totalmente ausentes. Das passagens citadas, parece ficar claro que as margens de lucro (e, com

\footnotetext{
${ }^{8} \mathrm{O}$ preço iniciado em $P$ refere-se ao preço do produto final do gênero; e o iniciado em $N$ referese ao preço dos insumos nacionais do gênero. Os códigos são os seguintes: ALIM (alimentos), BOR (borracha), MAT (material de transporte), MECA (mecânica), MECO (material elétrico e de comunicação), META (metalúrgica), PLAST (plásticos), QUIM (química), TEXTIL (têxtil) e MNM (minerais não metálicos).
} 
elas, os graus de monopólio) são decididos a partir de determinantes exclusivamente institucionais, o que vai de encontro à abordagem kaleckiana do grau de monopólio.

Das equações (3) a (5) acima pode-se concluir que o grau de monopólio do cliente é inversamente proporcional ao grau de monopólio do fornecedor, mantido o resto constante. Se pudermos fazer a hipótese de que o fornecedor tem como seus próprios fornecedores vendedores de matéria-prima concorrenciais, eliminamos o problema da determinação do preço de seus insumos (aqui não ocorreria o caso de um novo oligopólio bilateral, mas de um oligopsônio). Podemos considerar que tanto o cliente como o fornecedor, a princípio, estariam direcionando a barganha mais a seu favor, quanto maiores fossem os graus de liberdade que tivessem. Aceita essa última hipótese, poderíamos afirmar que a significância da história do preço do fornecedor na formação de preço do cliente (ou vice-versa) indicaria que o fornecedor (cliente) teria maior poder de decisão na barganha intersetorial, pois seus graus de liberdade na formação do próprio preço seriam maiores (ou viceversa). Cabe ressaltar que essa maior liberdade poderia ser usada para aumentar o próprio grau de monopólio ou diminuí-lo (na hipótese de um desconto, por exemplo).

Se pudermos caracterizar adequadamente o problema econômico da barganha pelos preços $p_{t}^{c}$ e $p_{t}^{f}$, como feito acima, seguindo Hendry (1997:175-176), a existência de causalidade de Granger entre essas variáveis estaria indicando que a história da primeira ou da segunda (ou ainda de ambas) seria importante para a formação da outra (ou de ambas). Assim, o teste de causalidade de Granger estaria indicando a existência (ou inexistência) de uma influência de certo grau de monopólio na determinação do outro.

Caberia a indagação de por que fazer testes de causalidade de Granger e não tentar medir diretamente, como faz Azzam (1996), a barganha intersetorial entre empresas oligopolizadas. A resposta é que, em Kalecki, não existe uma interação entre oferta e demanda de cada participante da barganha que nos possibilite estabelecer elasticidades-preço de demanda e oferta entre fornecedor e cliente como faz Azzam (1996). Além disso, não existe em Kalecki o custo marginal, que é nulo, dada a hipótese de custos unitários constantes. Dessa forma, o preço resultante da barganha é um resultado de poderes de mercado que se confrontam através de variáveis institucionais (ver, por exemplo, os fatores que influenciam o grau de monopólio em Kalecki (1983b)). Não há uma variável exógena no sentido enfatizado por Christ (1966), 'apud' Nakane (1994), quer dizer, uma variável cujo valor em cada período seja estatisticamente independente dos valores das disturbâncias no modelo em todos os períodos. Portanto, nessa barganha intersetorial não existem 
variáveis cuja exogeneidade pudesse ser diretamente testada. Resta a possibilidade de um teste indireto, através da causalidade de Granger como proposto.

\subsection{A definição de Granger-causalidade ${ }^{9}$}

O teste de causalidade de Granger foi efetuado em duas etapas: do preço do produto final contra o preço dos insumos e destes contra o preço do produto final. Carneiro (1997) sugere que se inicie por um número grande de defasagens e se vá paulatinamente as reduzindo, até minimizar a estatística de Scharwz (1978), 'apud' Carneiro (1997). Esse será o procedimento seguido aqui, a partir de Carneiro (1997) e Conceição et alii (1998).

Quanto à mudança estrutural, estimamos cada equação e testamos sua estabilidade pelo teste de Chow recursivo ${ }^{10}$ (do início para o fim da série, e do fim para o início da série). Se detectada instabilidade estrutural, acrescentamos 'dummies' no modelo até eliminar a instabilidade. Então, testamos se os valores defasados dos regressores cuja causalidade se quer testar são conjuntamente diferentes de zero.

O teste usado para testar a significância conjunta de cada grupo de coeficientes foi o teste F.

\subsection{A construção das séries}

Como desejávamos testar a relação de causalidade nas relações intersetoriais, procuramos construir, por gênero (IBGE) da indústria de transformação, séries de índices de preços de insumos nacionais e de preços de produtos finais.

A série de índices de preços de insumos nacionais foi construída a partir das seguintes etapas:

\footnotetext{
${ }^{9}$ Optamos por trabalhar apenas com o teste de causalidade original de Granger não é objetivo deste estudo fazer um teste multivariado, pois não estipulamos nenhuma equação de formação de preços - apenas procuramos testar a causalidade bivariada entre preços finais e preço de insumos nacionais. Tendo em vista esse último aspecto, não exploramos o teste de Hsiao (1981), 'apud' Ferreira (1993). Além disso, a vantagem que esse último teste teria, ao podermos definir o número ótimo de defasagens por meio da minimização do erro final de predição (EFP), não nos seria de grande valia, pois já trabalhamos com o número ótimo de defasagens por intermédio do critério de Schwarz, como sugerido por Carneiro (1997).

${ }^{10}$ Ver Doornik e Hendry (1994:328-329).
} 
- atribuiu-se aos gêneros considerados o IPA-OG correspondente (as colunas relativas a cada gênero estão apresentadas na tabela 6 , no anexo). No caso dos gêneros Química e Têxtil, a correspondência mais adequada exigiu que se montasse um índice Laspeyres a partir dos setores apresentados na tabela 6. Os pesos usados foram os VP's (Valores de Produção) do Censo Industrial de 1985 (as classes correspondentes a cada setor estão também relacionadas na tabela 6). No gênero Produtos Alimentares, o índice não inclui o setor Bebidas, apesar da agregação dos gêneros a partir dos produtos da matriz insumo-produto incluir o produto Bebidas. Duas justificativas podem atenuar essa imprecisão: primeiro, o VP de Bebidas representa menos de 7\% do VP de Produtos Alimentares no Censo Industrial de 1985; segundo, Produtos Alimentares não é insumo relevante para nenhum dos demais gêneros, não influenciando os testes desejados.

- a partir dos IPA-OG's atribuídos (e dos índices construídos), montou-se um índice de Laspeyres considerando, para cada gênero, os cinco principais gêneros fornecedores de insumos. A referência para essa determinação foi a Matriz B da matriz insumo-produto de 1995 (IBGE), adaptada para uma agregação por gêneros, a partir da classificação a nível 80 do IBGE (os resultados da agregação estão apresentados no anexo). Para tanto, considerou-se os VP's das atividades a nível 80 apresentados na tabela 2 da matriz de insumo-produto de 1995 do IBGE, que foram agregados para corresponder aos gêneros considerados. Os pesos dos índices de Laspeyres foram a parcela relativa de cada um dos cinco gêneros escolhidos no total do consumo de insumos nacionais de cada gênero considerado.

As séries de índices de preços de produtos correspondem aos IPA-OG's relacionados na tabela 6, com a exceção dos gêneros Química e Têxtil, como explicado acima.

Ainda no anexo, a tabela 5 apresenta os produtos considerados na agregação de gêneros industriais, a partir da matriz insumo-produto de 1985.

Tanto o índice de preço de insumos quanto o índice de preço do produto final de cada gênero foram deflacionados pelo $I G P-D I$, já que esse último índice apresenta metodologia semelhante à do IPA-OG. A deflação se justifica quando observamos que, no período amostral, ocorreram desde deflação até valores próximos a hiperinflação na dinâmica dos preços industriais. Uma série não deflacionada aumentaria o grau de integração, reduzindo a potência dos testes de raiz unitária e diminuindo os graus de liberdade.

Construímos, assim, séries mensais, de 1978.1 a 1998.12, para os seguintes 
gêneros: transformação de produtos de minerais não metálicos, metalúrgica, mecânica, material elétrico e de comunicação, material de transporte, borracha, química, produtos de matérias plásticas, têxtil e produtos alimentares.

\subsection{Testes de raiz unitária}

Na tabela 1, apresentamos os testes Dickey e Fuller Aumentado sem constante, com constante, e com constante e tendência. Partiu-se de vinte defasagens, que foram sendo reduzidas uma a uma, mantido o período amostral constante, até se alcançar a última defasagem significativa pela estatística t. Na tabela 1, os índices ** $\mathrm{e}^{*}$ encontrados denotam a significância das estatísticas do $A D F$ em nível de $1 \%$ e $5 \%$, respectivamente. A variável iniciada em $\mathrm{P}$ refere-se ao índice de preço do produto final; a iniciada em $\mathrm{N}$ refere-se ao índice de preço do insumo nacional; e a iniciada em $\mathrm{D}$, à primeira diferença, seja do índice de preço do produto final ou do insumo.

Os resultados da tabela 1 devem ser aceitos com cuidado. De fato, simulações de Monte Carlo têm mostrado que a potência dos testes $A D F$ é muito pequena, pois há uma indecisão desses testes para distinguir entre um processo com raiz unitária e outro próximo a uma raiz unitária. Além disso, eles têm baixa potência para distinguir entre um processo estacionário com tendência e outro não estacionário com 'drift'. Essas limitações do teste $A D F$ são relevantes e podem ser críticas se omitirmos, do teste, o intercepto ou a tendência, pois a potência do teste cai a zero quando o processo gerador dos dados contém aqueles elementos. Esse é um problema complexo, pois, como enfatiza Enders (1995), os testes para raízes unitárias dependem da presença de regressores determinísticos e os testes para presença de regressores determinísticos dependem da presença de uma raiz unitária. Entretanto, como enfatiza Enders (1995), se é possível saber que o processo gerador dos dados contém uma tendência e/ou intercepto, a hipótese nula da existência de uma raiz unitária pode ser testada usando-se a distribuição normal padronizada. Utilizamos esse procedimento (Enders, 1995:256-7). 
Tabela 1

Resultados de Testes ADF - 1978/1998

\begin{tabular}{|c|c|c|c|c|c|c|}
\hline Série & $\begin{array}{c}\text { Resultado s/ } \\
\text { constante }\end{array}$ & $\begin{array}{l}\text { Número de } \\
\text { defasagens }\end{array}$ & $\begin{array}{c}\text { Resultado c/ } \\
\text { constante }\end{array}$ & $\begin{array}{l}\text { Número de } \\
\text { defasagens }\end{array}$ & $\begin{array}{l}\text { Resultado c/ } \\
\text { const. e tend. }\end{array}$ & $\begin{array}{l}\text { Número de } \\
\text { defasagens }\end{array}$ \\
\hline PALIM & $-0,2639$ & 7 & $-1,7750$ & 7 & $-2,0823$ & 7 \\
\hline DPALIM & $-8,0971^{* *}$ & 6 & $-8,0808^{* *}$ & 6 & $-8,1472^{* *}$ & 6 \\
\hline NALIM & 0,3222 & 13 & $-2,9170^{*}$ & 4 & $-3,1947$ & 4 \\
\hline DNALIM & $-5,0871^{* *}$ & 12 & $-5,1059^{* *}$ & 12 & $-5,1033^{* *}$ & 12 \\
\hline PMECA & $-0,8281$ & 13 & $-0,9641$ & 13 & $-1,2252$ & 13 \\
\hline DPMECA & $-6,0305^{* *}$ & 12 & $-6,0658^{* *}$ & 12 & $-6,1170^{* *}$ & 12 \\
\hline NMECA & $-4,1997^{* *}$ & 20 & $-2,7817$ & 20 & $-1,6498$ & 20 \\
\hline DNMECA & - & - & $-4,5113^{* *}$ & 19 & $-5,1610^{* *}$ & 19 \\
\hline PMNM & 0,0048 & 4 & $-2,1724$ & 1 & $-2,3393$ & 1 \\
\hline DPMNM & $-8,1853^{* *}$ & 3 & $-8,1780^{* *}$ & 3 & $-8,1905^{* *}$ & 3 \\
\hline NMNM & $-1,0075$ & 9 & $-0,5993$ & 9 & $-3,2201$ & 9 \\
\hline DNMNM & $-5,8328^{* *}$ & 8 & $-5,9025^{* *}$ & 8 & $-5,9511^{* *}$ & 8 \\
\hline PBOR & $-0,8765$ & 15 & $-1,4297$ & 15 & $-2,5806$ & 10 \\
\hline DPBOR & $-3,6453^{* *}$ & 14 & $-3,6750^{* *}$ & 14 & $-3,6702^{*}$ & 14 \\
\hline NBOR & $-1,0946$ & 17 & $-0,5905$ & 17 & $-2,5674$ & 10 \\
\hline DNBOR & $-3,9754^{* *}$ & 16 & $-4,0941^{* *}$ & 16 & $-4,1195^{* *}$ & 16 \\
\hline PMAT & $-1,1710$ & 8 & $-1,7801$ & 14 & $-3,3338$ & 14 \\
\hline DPMAT & $-6,1073^{* *}$ & 7 & $-6,1692^{* *}$ & 7 & $-6,1555^{* *}$ & 7 \\
\hline NMAT & $-2,4814$ & 16 & $-1,5801$ & 14 & $-2,8593$ & 14 \\
\hline DNMAT & $-3,3264^{* *}$ & 20 & $-4,3624^{* *}$ & 15 & $-4,4579^{* *}$ & 15 \\
\hline PMECO & $-1,9019$ & 12 & $-0,0509$ & 12 & $-2,4865$ & 12 \\
\hline DPMECO & $-4,9856^{* *}$ & 11 & $-5,4019^{* *}$ & 11 & $-5,4401^{* *}$ & 11 \\
\hline NMECO & $3,5229^{* *}$ & 17 & $-0,7667$ & 17 & $-3,8707^{*}$ & 11 \\
\hline DNMECO & - & - & $-5,3843^{* *}$ & 16 & $-5,3871^{* *}$ & 16 \\
\hline PMETA & $-4,1917^{* *}$ & 20 & $-3,9871^{* *}$ & 20 & $-2,1124$ & 20 \\
\hline DPMETA & - & - & - & - & $-4,9837^{* *}$ & 19 \\
\hline NMETA & $-4,0832^{* *}$ & 20 & $-3,3016^{*}$ & 20 & $-1,2041$ & 20 \\
\hline DNMETA & - & - & $-3,6594^{* *}$ & 19 & $-4,8132^{* *}$ & 19 \\
\hline PPLAST & $-0,8181$ & 11 & $-0,9217$ & 13 & $-2,0628$ & 13 \\
\hline DPPLAST & $-5,4941^{* *}$ & 10 & $-5,5364^{* *}$ & 10 & $-5,6893^{* *}$ & 10 \\
\hline NPLAST & $-0,8553$ & 1 & $-0,7060$ & 1 & $-2,5414$ & 1 \\
\hline DNPLAST & $-18,3190^{* *}$ & 0 & $-18,314^{* *}$ & 0 & $-17,9420^{* *}$ & 0 \\
\hline PQUIM & $-0,7219$ & 1 & $-0,8410$ & 1 & $-2,5706$ & 1 \\
\hline DPQUIM & $-19,7930^{* *}$ & 0 & $-19,7710^{* *}$ & 0 & $-19,7860^{* *}$ & 0 \\
\hline NQUIM & $-1,1440$ & 20 & $-0,8620$ & 20 & $-3,1538$ & 20 \\
\hline DNQUIM & $-2,8699^{* *}$ & 19 & $-3,0142^{*}$ & 19 & $-2,9568$ & 19 \\
\hline PTEXTIL & $-3,1030^{* *}$ & 19 & $-2,2485$ & 19 & $-3,6451^{*}$ & 9 \\
\hline DPTEXTIL & - & - & $-3,9412^{* *}$ & 20 & $-4,0491^{* *}$ & 20 \\
\hline NTEXTIL & $-3,0363^{* *}$ & 13 & $-2,2808$ & 13 & $-3,9303^{*}$ & 13 \\
\hline DNTEXTIL & - & - & $-4,6267^{* *}$ & 12 & $-4,8574^{* *}$ & 12 \\
\hline
\end{tabular}

O procedimento adotado neste artigo foi fazer o teste ADF padrão (ver tabela 1) e, adicionalmente, fazer o procedimento sugerido por Enders (1995), além de, para testar a presença de quebra estrutural, fazer o teste de Perron (1989). No último teste, estabelecemos como possíveis quebras estruturais a primeira e a segunda maxidesvalorizações cambiais de fins da década de 70 e início da década de 80, os planos Cruzado, Bresser, Verão, Collor I, Collor II e Real, além de alguma quebra sugerida por inspeção visual. 
Esses procedimentos indicaram que, salvo aquelas séries presentes na tabela 2, todas as séries são I(1). A única exceção é a série NQUIM, que, apesar de constar na tabela 2, apresentou quebra estrutural na primeira diferença, sendo portanto $\mathrm{I}(1)$.

Tabela 2

Resultados do teste de Perron - 1978.1/1998.12

\begin{tabular}{lcccc}
\hline Série & $\begin{array}{c}\text { Tipo de } \\
\text { quebra }\end{array}$ & $\begin{array}{c}\text { Data da } \\
\text { quebra }\end{array}$ & $t_{\alpha}$ & $\begin{array}{c}\text { Número de } \\
\text { defasagens }\end{array}$ \\
\hline PMETA & $\mathrm{B}$ & 1986.2 & $-4,1310$ & 15 \\
NMETA & $\mathrm{B}$ & 1987.9 & $-4,1020$ & 15 \\
PMNM & $\mathrm{B}$ & 1989.1 & $-3,9600$ & 1 \\
PALIM & $\mathrm{A}$ & 1986.2 & $-3,9620$ & 7 \\
NALIM & $\mathrm{C}$ & 1987.9 & $-4,9570$ & 11 \\
NMAT & $\mathrm{A}$ & 1985.1 & $-4,0360$ & 14 \\
NMECA & $\mathrm{B}$ & 1986.2 & $-4,9240$ & 19 \\
DNQUIM & $\mathrm{B}$ & 1986.2 & $-3,9590$ & 19 \\
\hline Fonte: Elaboração própria.
\end{tabular}

\subsection{Resultados dos testes de causalidade}

Na tabela 3 abaixo, apresentamos os testes de co-integração para cada teste de causalidade. As linhas onde aparece I no setor se referem à causalidade de insumo para produto, as em que aparece II se referem à de produto para insumo. Mostramos apenas os teste de autovalor e de traço, por economia de espaço, já que os vetores de co-integração e de ajustamento são dispensáveis para a análise de causalidade aqui feita. Todos as equações co-integraram a $1 \%$ (referência ${ }^{* *}$ ) e apenas Alimentos a $5 \%$ (referência *).

Na tabela 4, apresentamos os resultados dos testes de causalidade de Granger para cada gênero industrial. Os resultados apresentados referem-se aos valores já ajustados (ajuste estrutural). Os níveis de significância são indicados como na tabela 3. Lembramos que a causalidade, nesse teste, não está implicando uma relação de causa e efeito, no sentido transitivo, mas que há uma precedência temporal e uma referência informacional de uma variável para outra. 
Tabela 3

\begin{tabular}{|c|c|c|c|c|c|c|c|}
\hline \multicolumn{8}{|c|}{ Testes de Johansen de Cointegração } \\
\hline \multirow[b]{2}{*}{ Setor } & \multirow[b]{2}{*}{ Posto } & \multicolumn{3}{|c|}{ Teste de Maior Autovalor } & \multicolumn{3}{|c|}{ Testes de Traço } \\
\hline & & $\mathrm{a}$ & $\mathrm{b}$ & $95 \%$ & $\mathrm{c}$ & $\mathrm{d}$ & $95 \%$ \\
\hline \multirow{2}{*}{ ALIM I } & 0 & 9,36 & 8,74 & 11,40 & $15,83^{*}$ & $14,79^{*}$ & 12,5 \\
\hline & $<1$ & $6,47^{*}$ & $6,04^{*}$ & 3,80 & $6,47^{*}$ & $6,04^{*}$ & 3,80 \\
\hline \multirow[t]{2}{*}{ ALIM II } & $-\bar{c}^{-}$ & $33,86^{* *}$ & $32,47^{* *}$ & 11,40 & $43,87^{* *}$ & $42,06 * *$ & 12,50 \\
\hline & $\leq 1$ & $10,01^{* *}$ & $9,60 * *$ & 3,80 & $10,01 * *$ & $9,60^{* *}$ & 3,80 \\
\hline \multirow[t]{2}{*}{ MAT I } & 0 & $21,41^{* *}$ & $18,28^{* *}$ & 11,40 & $29,28 * *$ & $25,01 * *$ & 12,50 \\
\hline & $\leq 1$ & $7,87^{* *}$ & $6,72^{* *}$ & 3,80 & $7,87^{* *}$ & $6,72^{* *}$ & 3,80 \\
\hline \multirow[t]{2}{*}{ MAT II } & 0 & $38,42^{* *}$ & $35,45^{* *}$ & 11,40 & $44,71^{* *}$ & $41,26^{* *}$ & 12,50 \\
\hline & $\leq 1$ & $6,30^{*}$ & $5,81^{*}$ & 3,80 & $6,30^{*}$ & $5,81^{*}$ & 3,80 \\
\hline \multirow[t]{2}{*}{ BOR I } & 0 & $19,24^{* *}$ & $16,79^{* *}$ & 11,40 & $31,98 * *$ & $27,89 * *$ & 12,50 \\
\hline & $\leq 1$ & $12,73^{* *}$ & $11,10^{* *}$ & 3,80 & $12,73^{* *}$ & $11,10^{* *}$ & 3,80 \\
\hline \multirow[t]{2}{*}{ BOR II } & -0 & $21,61^{* *}$ & $18,85^{* *}$ & 11,40 & $33,79 * *$ & $29,48^{* *}$ & 12,5 \\
\hline & $\leq 1$ & $12,19 * *$ & $10,63^{* *}$ & 3,80 & $12,19 * *$ & $10,63^{* *}$ & 3,80 \\
\hline \multirow[t]{2}{*}{ MECA I } & 0 & $29,16^{* *}$ & $25,96 * *$ & 11,40 & $48,75^{* *}$ & $43,40^{* *}$ & 12,50 \\
\hline & $\leq 1$ & $19,60^{* *}$ & $17,45^{* *}$ & 3,80 & $19,60 * *$ & $17,45 * *$ & 3,80 \\
\hline \multirow[t]{2}{*}{ MECA II } & 0 & $21,28^{* *}$ & $18,19^{* *}$ & 11,40 & $33,77^{* *}$ & $28,86^{* *}$ & 12,50 \\
\hline & $\leq 1$ & $12,49^{* *}$ & $10,68^{* *}$ & 3,80 & $12,49 * *$ & $10,68^{* *}$ & 3,80 \\
\hline \multirow[t]{2}{*}{ META I } & -0 & $24,20 * *$ & $20,87^{* *}$ & 11,40 & $38,42^{* *}$ & $32,84^{* *}$ & 12,5 \\
\hline & $\leq 1$ & $14,00^{* *}$ & $11,97 * *$ & 3,80 & $14,00 * *$ & $11,97 * *$ & 3,80 \\
\hline \multirow[t]{2}{*}{ META II } & 0 & $23,81^{* *}$ & $20,13^{* *}$ & 11,40 & $38,05 * *$ & $32,17^{* *}$ & 12,5 \\
\hline & $\leq 1$ & $14,24^{* *}$ & $12,04^{* *}$ & 3,80 & $14,24^{* *}$ & $12,04^{* *}$ & 3,80 \\
\hline \multirow[t]{2}{*}{ MECO I } & 0 & 32,16 ** & $28,91^{* *}$ & 11,40 & $52,49 * *$ & $47,20 * *$ & 12,50 \\
\hline & $\leq 1$ & $20,33^{* *}$ & $18,28^{* *}$ & 3,80 & $20,33^{* *}$ & $18,28 * *$ & 3,80 \\
\hline \multirow[t]{2}{*}{ MECO II } & 0 & $22,99 * *$ & $19,22 * *$ & 11,40 & $37,57^{* *}$ & $31,74^{* *}$ & 12,50 \\
\hline & $\leq 1$ & $14,80^{* *}$ & $12,32^{* *}$ & 3,80 & $14,58^{* *}$ & $12,32 * *$ & 3,80 \\
\hline \multirow[t]{2}{*}{ MNM I } & 0 & $126,00^{* *}$ & $123,90 * *$ & 11,40 & $144,00 * *$ & $141,70^{* *}$ & 12,50 \\
\hline & $\leq 1$ & $18,02^{* *}$ & $17,73^{* *}$ & 3,80 & $18,02^{* *}$ & $17,73^{* *}$ & 3,80 \\
\hline \multirow[t]{2}{*}{ MNM II } & 0 & $37,95^{* *}$ & $35,12^{* *}$ & 11,40 & $37,96^{* *}$ & $35,13^{* *}$ & 12,50 \\
\hline & $\leq 1$ & 0,01 & 0,01 & 3,80 & 0,01 & 0,01 & 3,80 \\
\hline \multirow[t]{2}{*}{ TEXTIL I } & 0 & $34,13^{* *}$ & $31,58^{* *}$ & 11,40 & $56,32^{* *}$ & $52,11^{* *}$ & 12,50 \\
\hline & $\leq 1$ & $22,19 * *$ & $20,53^{* *}$ & 3,80 & $22,19 * *$ & $20,53^{* *}$ & 3,80 \\
\hline \multirow[t]{2}{*}{ TEXTIL II } & 0 & $22,63^{* *}$ & $20,15^{* *}$ & 11,40 & $35,80 * *$ & $31,87^{* *}$ & 12,50 \\
\hline & $\leq 1$ & $13,70^{* *}$ & $11,72^{* *}$ & 3,80 & $13,17^{* *}$ & $11,72^{* *}$ & 3,80 \\
\hline \multirow[t]{2}{*}{ QUIM I } & 0 & $19,3^{* *}$ & $15,95^{* *}$ & 11,40 & $24,61^{* *}$ & $20,33^{* *}$ & 12,50 \\
\hline & $\leq 1$ & $5,31^{*}$ & $4,38^{*}$ & 3,80 & $5,31^{*}$ & $4,38^{*}$ & 3,80 \\
\hline \multirow[t]{2}{*}{ QUIM II } & 0 & $21,07^{* *}$ & $17,41 * *$ & 11,40 & $26,60^{* *}$ & $21,98 * *$ & 12,50 \\
\hline & $\leq 1$ & $5,53^{*}$ & $4,57^{*}$ & 3,80 & $5,53^{*}$ & $4,57^{*}$ & 3,80 \\
\hline PLAST I & 0 & $24,88^{* *}$ & $20,79 * *$ & 11,40 & $39,22 * *$ & $32,76^{* *}$ & 12,50 \\
\hline & $\leq 1$ & $14,33^{* *}$ & $11,97 * *$ & 3,80 & $14,33^{* *}$ & $11,97 * *$ & 3,80 \\
\hline PLAST II & 0 & $203,70^{* *}$ & $201,90 * *$ & 11,40 & $380,00 * *$ & $376,70^{* *}$ & 12,50 \\
\hline & $\leq 1$ & $176,30 * *$ & $174,80^{* *}$ & 3,80 & $176,30 * *$ & $174,80^{* *}$ & 3,80 \\
\hline $\begin{array}{l}\text { Elaboração } \\
\text { Obs: a = - } \\
\mathrm{b}=-(T- \\
\mathrm{c}=-T \Sigma \log ( \\
\mathrm{d}=-(T-n\rangle\end{array}$ & $\begin{array}{l}\text { l) } \log (1 \\
-\gamma)\end{array}$ & $\gamma)$ & & & & & \\
\hline
\end{tabular}


Tabela 4

Resultado do teste de causalidade de Granger

\begin{tabular}{|c|c|c|c|c|c|c|}
\hline & \multicolumn{3}{|c|}{ Causalidade de Insumo para Produto } & \multicolumn{3}{|c|}{ Causalidade de Produto para Insumo } \\
\hline Gênero & Estatística $\mathrm{F}$ & $\begin{array}{l}\text { Número de } \\
\text { Defasagens } \\
\text { Produto }\end{array}$ & $\begin{array}{c}\text { Número de } \\
\text { Defasagens } \\
\text { Insumo }\end{array}$ & Estatística F & $\begin{array}{c}\text { Número de } \\
\text { Defasagens } \\
\text { Produto }\end{array}$ & $\begin{array}{c}\text { Número de } \\
\text { Defasagens } \\
\text { Insumo }\end{array}$ \\
\hline Têxtil & 0,3024 & 9 & 1 & 1,4616 & 9 & 13 \\
\hline Química & 1,1134 & 1 & 20 & 0,2115 & 1 & 20 \\
\hline $\begin{array}{l}\text { Produtos de matérias } \\
\text { plásticas }\end{array}$ & $1,6620^{* *}$ & 11 & 19 & $12,7300^{* * *}$ & 1 & 1 \\
\hline $\begin{array}{l}\text { Transf. de minerais } \\
\text { não metálicos }\end{array}$ & 0,1998 & 2 & 1 & $10,5310^{* * *}$ & 2 & 9 \\
\hline $\begin{array}{l}\text { Material elétrico e } \\
\text { de comunic. }\end{array}$ & 1,6200 & 12 & 1 & $2,1669^{* * *}$ & 18 & 17 \\
\hline Metalúrgica & 1,0524 & 17 & 16 & 0,7366 & 18 & 17 \\
\hline Mecânica & 1,4726 & 13 & 2 & $18,9900^{* * *}$ & 1 & 17 \\
\hline Material de transporte & $1,7647^{* *}$ & 8 & 17 & $3,1318^{*}$ & 1 & 9 \\
\hline Borracha & $12,1470^{* * *}$ & 15 & 1 & $2,0246^{* *}$ & 15 & 7 \\
\hline Produtos alimentares & 2,2081 & 8 & 1 & 1,417 & 1 & 5 \\
\hline
\end{tabular}

Elaboração própria.

Obs: $* * *$ (significativo a $1 \%$ )

** (significativo a $5 \%$ ) e

* (significativo a $10 \%$ ).

Notamos que nos gêneros transformação de minerais não metálicos, material elétrico e de comunicação e mecânica, a resolução da barganha no mercado de fatores dá-se geralmente por uma precedência temporal e referência informacional dos preços dos produtos finais para os preços dos insumos. Esse resultado é muito semelhante ao indicado por Bain (1952), quando afirma que, sob uma barganha de oligopólio bilateral, geralmente os compradores são favorecidos, pois podem agir independentemente e jogar duro quando buscam oferta, enquanto os vendedores, para resistirem a essa pressão dos compradores, precisam ter um conluio efetivo nos preços, o que geralmente é mais difícil.

Em três gêneros (borracha, produtos de matérias plásticas e material de transporte) ocorre dupla causalidade. No caso dos dois primeiros gêneros, o principal fornecedor é Química. Nota-se que esse gênero está entre os mais concentrados da indústria. Além disso, foi um setor dominado por empresas estatais até o início das privatizações na década de 90 . Essas duas características dão ao setor forte poder de barganha e rigidez de preços nas relações intersetoriais. Dessa forma, a tendência de o comprador determinar os preços (segundo a análise de Bain) parece se sobrepor ao poder (inclusive estatal) de determinar o sentido da barganha.

O caso de materiais de transporte parece ser semelhante. Nesse setor, considerando-se os insumos que não são autoconsumo, o principal fornecedor é o gênero metalúrgica, fundamentalmente siderurgia. Esse setor, a exemplo do da Química, é não apenas altamente concentrado, como também preponderantemente estatal até meados da década de 90 . Assim, esse setor também tem forte poder de barganha 
e rigidez de preço nas relações intersetoriais. Dessa forma, repete-se para materiais de transporte a tendência do comprador de determinar os preços (segundo a análise de Bain), mas sobreposta ao poder (inclusive estatal) dos fornecedores de determinar o sentido da barganha.

Os gêneros metalúrgica, química e têxtil não apresentam nenhuma causalidade. Isso não quer dizer que os insumos não entrem no custo do produto final. Isso quer dizer apenas que não há precedência temporal entre as duas formações de preço. A explicação para isso parece ser que esses três gêneros são os que mais compram de si mesmos na indústria, ou seja, são os mais verticalizados. Assim, o teste não acusa nenhuma precedência temporal na barganha intersetorial.

O gênero produtos alimentares também não apresenta causalidade em nenhuma direção. Contudo, a razão aqui parece ser outra. O mercado de fatores aqui cota, na maioria dos casos, produtos com preços altamente influenciados por preços internacionais de 'commodities'. Dessa forma, tanto compradores quanto vendedores parecem ter pouco poder de influenciar temporalmente um ao outro.

Devemos enfatizar, contudo, que os resultados apresentados são apenas indicativos. Somente uma análise mais desagregada, como os estudos de caso, poderia traçar um perfil mais exato de causalidade de preços. Essa tarefa está além do escopo deste estudo, mas provavelmente será objeto de estudos futuros.

\section{Conclusão}

Ao longo deste artigo tentamos mostrar teoricamente que o resultado da barganha intersetorial pelo preço de insumos pode alterar o grau de monopólio do setor industrial ou de toda a indústria. Depois, testamos a causalidade entre fornecedores e compradores de dez gêneros industriais. Os resultados parecem coerentes com as afirmativas de Bain (1952).

Esse trabalho procura mostrar que o estudo de formação de preços na indústria deve ser feito tendo em vista suas cadeias produtivas ou complexos industriais, pois há uma estrutura nos encadeamentos intersetoriais relevante para a determinação de preços. A desconsideração dos encadeamentos pode levar a resultados diferentes dos corretos. 


\section{Anexo}

Tabela A.1

Agregação de Produto por Gênero

\begin{tabular}{lc}
\hline Gênero & Código de Produto* \\
\hline Agropecuária & $0101,0102,0103,0104,0105,0106$, \\
& $0107,0108,0109,0110,0199$ \\
Extrativa Mineral & 0201,0202 \\
Transformação de Minerais não Metálicos & 0401 \\
Metalúrgica & $0501,0502,0701,0601$ \\
Mecânica & 0801,0802 \\
Material Elétrico e de Comunicação & 1001,1101 \\
Material de Transporte & 1201,1301 \\
Borracha & 1601 \\
Química & $1701,1702,1801,1802,1803,1804$, \\
& $1805,1806,1901,1902,1903$ \\
Produtos de Matéria Plástica & 2101 \\
Têxtil & $2201,2202,2203,2204$ \\
Produtos Alimentares & $2802,2901,3001,3002,3101$ \\
&
\end{tabular}

Tabela A.2

Colunas do IPA-OG e Agregação por Gênero

\begin{tabular}{lcc}
\hline Gênero & Coluna IPA-OG & $\begin{array}{c}\text { Número de Classes do Censo } \\
\text { Industrial de 1985 }\end{array}$ \\
\hline 1. Agropecuária & 18 & \\
2. Extrativa Mineral & 28 & \\
3. Transformação de Minerais & 30 & \\
não Metálicos & 31 & \\
4. Metalúrgica & 34 & 302 \\
5. Mecânica & 38 & 321 \\
6. Material Elétrico e de & & 325 \\
Comunicação & 42 & \\
7. Material de Transporte & 51 & \\
8. Borracha & 54 & \\
9. Química & 55 & \\
$\quad 9.1$ Combustíveis e Lubrific. & 57 & $373,374,375,376,377,379$ \\
$\quad 9.2$ Tintas e Vernizes & 56 & 380,378 \\
$\quad 9.3$ Fertilizantes & 60 & 383 \\
10. Produtos de Matéria Plástica & 61 & \\
11. Têxtil & 62 & \\
$\quad$ 11.1 Tecidos e Fios Naturais & 70 & \\
11.2 Tecidos e Fios Artificiais & & \\
11.3 Malharia & & \\
12. Produtos Alimentares & & \\
\end{tabular}


Tabela A.3

Matriz de Coeficientes B (Insumos Nacionais) a partir da Matriz Insumo-Produto de 1995

\begin{tabular}{|c|c|c|c|c|c|c|c|c|c|c|c|c|}
\hline Gênero & MNM & META & MECA & MECO & MAT & $\mathrm{BOR}$ & QUIM & FARM & PLAST & TEXTIL & VECA & ALIM \\
\hline AGRO & 0,00641 & 0,01564 & 0 & 0 & 0 & 0,04406 & 0,0354 & 0,0018 & 0 & 0,04912 & 0,00143 & 0,35366 \\
\hline EXTRAT & 0,04761 & 0,02595 & 0 & 0,00247 & 0 & 0,00113 & 0,06841 & 0,0027 & 0 & 0 & 0,00031 & 0,00175 \\
\hline MNM & 0,19863 & 0,00628 & 0,00612 & 0,01685 & 0,00719 & 0,00032 & 0,00194 & 0,01841 & 0,00222 & 0,00009 & 0,00027 & 0,0057 \\
\hline META & 0,0243 & 0,38806 & 0,17777 & 0,121 & 0,15071 & 0,01169 & 0,01125 & 0,0089 & 0,00455 & 0,00426 & 0,00513 & 0,01339 \\
\hline MECA & 0,01949 & 0,02688 & 0,02751 & 0,03525 & 0,03522 & 0,01249 & 0,01614 & 0,00685 & 0,00931 & 0,0153 & 0,00396 & 0,00844 \\
\hline $\mathrm{MECO}$ & 0,00144 & 0,00269 & 0,02716 & 0,11065 & 0,00533 & 0,00077 & 0,00067 & 0,00017 & 0,00049 & 0,00055 & 0,00014 & 0,00024 \\
\hline MAT & 0,00002 & 0,00043 & 0,01531 & 0,00054 & 0,21654 & 0,00015 & 0,00002 & 0 & 0 & 0,00001 & 0,00001 & 0 \\
\hline BOR & 0,00293 & 0,00311 & 0,00906 & 0,00271 & 0,02834 & 0,24885 & 0,00129 & 0,00126 & 0,00238 & 0,00299 & 0,02103 & 0,00068 \\
\hline QUIM & 0.07971 & 0,03587 & 0,01669 & 0,02701 & 0,02367 & 0,15067 & 0,24074 & 0,11842 & 0.32054 & 0,08476 & 0,03295 & 0,01782 \\
\hline FARM & & 0 & 0 & 0 & 0 & 0 & 0,00092 & 0,00168 & 0 & 0 & 0 & 0,00119 \\
\hline PLAST & 0,0024 & 0,00209 & 0.0067 & 0,02491 & 0,01123 & 0,00142 & 0,00342 & 0,02004 & 0,05529 & 0,00647 & 0,02109 & 0,00808 \\
\hline TEXTIL & 0,00065 & 0,0001 & 0.0015 & 0.00072 & 0.00315 & 0.0384 & 0.00085 & 0,00066 & 0,0101 & 0,342 & 0,27776 & 0,00586 \\
\hline VECA & 0,00019 & 0,0003 & 0,00057 & 0,00025 & 0,00099 & $\begin{array}{l}0,00019 \\
0\end{array}$ & 0,00036 & 0,00025 & 0,00023 & 0,00053 & 0,06651 & 0,00024 \\
\hline ALIM & 0,00044 & 0,00019 & 0,00033 & 0,00021 & 0,00016 & 0,00016 & 0,01222 & 0,06942 & 0,00024 & 0,00077 & 0,03324 & 0,17823 \\
\hline
\end{tabular}

Fonte. Matriz Insumo-Produto 1995, IBGE

Legenda dos Gêneros: Agropecuária (AGRO), Extrativa Mineral (EXTRAT), Transformação de Minerais não Metálicos (MNM),

Metalúrgica (META), Mecânica (MECA), Material Elétrico e de Comunicação (MECO), Material de Transporte (MAT),

Borracha (BOR), Quimica (QUMM), Farmaceutica e Perfumaria (FARM), Produtos de Matéria Plástica (PLAST) 


\section{Referências}

Azzam, A. M. (1996). Estimating the degree of dominance in a bilateral oligopoly. Applied Economic Letters, 3:209-211.

Bain, J. S. (1952). Price Theory. John Wiley and Sons, New York.

Carneiro, F. G. (1997). A metodologia dos testes de causalidade em economia. Brasília: Departamento de Economia, UnB, Série Textos Didáticos n. 20.

Chenery, H. (1949). Engineering production functions. Quarterly Journal of Economics, pages 507-31.

Christ, C. F. (1966). Econometric Models and Methods. John Wiley and Sons, New York.

Conceição, J. C. P. R., Gasques, J. G., Carvalho, A., \& Conceição, P. H. Z. (1998). Relação entre PIB agrícola e crédito rural no Brasil: Aplicação do teste de causalidade de Granger. Anais do XXXVI Congresso Brasileiro de Economia e Sociologia Rural. Poços de Caldas.

Cowling, K. (1978). Monopoly, welfare and distribution. In Artis, M. J. \& Nobay, A. R. e., editor, Contemporary Economic Analysis. Croom Helm, London.

Doornik, J. A. \& Hendry, D. F. (1994). PcGive 8.0: Interactive Econometric Modelling System. International Thomson Publishing, London.

Enders, W. (1995). Applied Econometric Time Series. John Wiley \& Sons, New York.

Ferreira, A. H. B. (1993). Testes de Granger-causalidade para a balança comercial brasileira. Revista Brasileira de Economia, 47(1).

Galbraith, J. K. (1954). American Capitalism: The Concept of Countervailing Power. Houghton Mifflin Company, Boston.

Haguenauer, L., Araújo Jr, J. T., Prochnik, V., \& Guimarães, E. (1984). Os Complexos Industriais $\mathrm{Na}$ Economia Brasileira. IEI/UFRJ, Rio de Janeiro.

Hall, R. L. \& Hitch, C. J. (1988). A teoria dos preços e o comportamento empresarial. In Clássicos de Literatura Econômica. Ipea/Inpes, Rio de Janeiro.

Hendry, D. (1997). Dynamic Econometrics. Oxford University Press, New York. 
Hsiao, C. (1981). Autoregressive modelling and money-income causality detection. Journal of Monetary Economics, 7:85-106.

Kalecki, M. (1938). The determinants of distribution of the national income. Econometrica, 6(2).

Kalecki, M. (1943). Studies in Economic Dynamics. George Allen \& Unwin, London.

Kalecki, M. (1983a). Luta de classe e distribuição da renda nacional. In Crescimento e Ciclo Das Economias Capitalistas. Hucitec, São Paulo.

Kalecki, M. (1983b). Teoria Da Dinâmica Econômica. Abril Cultural, São Paulo.

Kriesler, P. (1987). Kalecki's Microanalysis. Cambridge University Press, New York.

Lerner, A. P. (1934). The concept of monopoly and the measurement of monopoly power. Review of Economic Studies, 1.

Liebeskind, J. P., Opler, T. C., \& Hatfield, D. E. (1996). Corporate restructuring and the consolidation of U.S. industry. The Journal of Industrial Economics, XLIV.

Nakane, M. I. (1994). Testes de Exogeneidade Fraca e Superexogeneidade Para a Demanda de Moeda No Brasil. BNDES, Rio de Janeiro.

Perron, P. (1989). The great crash, the oil schok prices, and the unit root hypothesis. Econometrica, 57(6).

Sawyer, M. (1985). The Economics of Michal Kalecki. Sharpe, New York.

Scharwz, G. (1978). Estimating the dimension of a model. Annals of Statistics.

Sraffa, P. (1988). As leis dos rendimentos sob condições de concorrência. In Clássicos de Literatura Econômica. Ipea/Inpes, Rio de Janeiro.

Sweezy, P. (1939). Demand under conditions of oligopoly. Journal of Political Economy, pages 568-73.

Willig, R. (1976a). Consumer surplus without apology. American Economic Review, 66:589-97.

Willig, R. (1976b). Integrability implications for locally constant demand elasticities. Journal of Economic Theory, 12:391-401. 